\title{
Pengelolaan Sampah Organik Rumah Pemotongan Hewan, Industri Tahu, Peternakan, dan Pasar di Kecamatan Krian, Kabupaten Sidoarjo.
}

\author{
As'adul Khoiri Waddin dan Arseto Yekti Bagastyo \\ Jurusan Teknik Lingkungan, Fakultas Teknik Sipil dan Perencanaan, Institut Teknologi Sepuluh Nopember (ITS) \\ Jl. Arief Rahman Hakim, Surabaya 60111 Indonesia \\ e-mail: bagastyo@enviro.its.ac.id
}

\begin{abstract}
Abstrak- Hampir lebih dari 60\% sampah yang dihasilkan di seluruh Indonesia merupakan sampah organik atau biasa disebut sampah sejenis rumah tangga. Sampah organik ini mempunyai potensi besar untuk dimanfaatkan sebagai bahan bahan yang berguna dan bernilai ekonomis, seperti kompos, biogas, dan sebagainya. Penelitian ini bertujuan untuk memperoleh data terkait timbulan dan komposisi sampah organik dari 4 (empat) proses kegiatan di Kecamatan Krian Kabupaten Sidoarjo, yaitu Rumah Pemotongan Hewan (RPH), Industri Tahu, Peternakan, dan Pasar. Setelah data diketahui, kemudian bisa dijadikan pertimbangan untuk pengolahan sampah yang tepat guna terutama ditinjau dari aspek finansial. Hasil penelitian sebagai berikut: Jumlah timbulan limbah padat sentra industri tahu; 5018,33 kg/hari untuk kapasitas produksi tinggi; 2412,92 kg/hari untuk kapasitas produksi sedang; dan 524 kg/hari untuk kapasitas produksi rendah. Untuk timbulan limbah padat sentra peternakan sapi perah yang berupa kotoran sapi adalah sebesar 3272,889 $\mathrm{kg} / \mathrm{hari}$; dan sisa pakan ternak adalah sebesar 261,133 kg/hari. Timbulan limbah padat Rumah Pemotongan Hewan (RPH) yang berupa isi rumen adalah sebesar 3539,98 kg/hari; dan darah sapi sebesar 754,65 kg/hari.Jumlah timbulan limbah padat pasar krian adalah sebesar 4947,89 kg/hari dengan komposisi: sampah biodegradable $(92,554 \%)$; dan lainnya $(7,446)$ non-biodegradable. Keuntungan yang didapat untuk pengolahan kompos dan RDF sebesar Rp. 253.938.445,00 per tahun. Untuk keuntungan biogas sebesar Rp. 131.613.525,00 dan Rp. 34.437.203,00 per tahun.
\end{abstract}

Kata Kunci-Sampah Organik, Timbulan dan Komposisi, Analisis Finansial.

\section{PENDAHULUAN}

$\mathrm{S}$ AMPAH diartikan sebagai bahan sisa, baik bahanbahan yang sudah tidak digunakan lagi (barang bekas) maupun bahan yang sudah diambil bagian utamanya yang dari segi ekonomis, sampah adalah bahan buangan yang tidak ada harganya dan dari segi lingkungan, sampah adalah bahan buangan yang tidak berguna dan banyak menimbulkan masalah pencemaran dan gangguan pada kelestarian lingkungan [1]. Sampah juga bisa diartikan sebagai sesuatu yang tidak dapat digunakan, tidak dipakai, tidak disenangi atau sesuatu yang terbuang yang berasal dari kegiatan manusia dan tidak terjadi dengan sendirinya [2].
Pengelolaan sampah sangat mutlak diperlukan untuk dapat mereduksi timbulan sampah yang ada. Apalagi dengan kondisi saat ini, dimana pertumbuhan penduduk bertambah pesat dan tingginya konsumsi masyarakat. Pengelolaan sampah dapat dapat berjalan optimal dikarenakan adanya peran serta masyarakat dan kontribusi pemerintah dalam pengadaan sarana dan prasarana.

Rata - rata pengelolaan sampah yang baik itu berada di kota-kota besar. Hal ini berbanding terbalik dengan kondisi yang terjadi, khususnya di daerah Kabupaten yang sebagian besar daerahnya masih pedesaan. Pengelolaan sampah di permukiman pedesaan banyak menerapkan pola individual. Pengelolaan sampah secara individual dilakukan dengan cara membakar, mengubur dan/atau membuangnya ke saluran air atau sungai [3]. Dalam penelitian ini dilakukan studi kasus di Kecamatan Krian, Kabupaten Sidoarjo.

Secara geografis, Kabupaten Sidoarjo merupakan salah satu Kabupaten di Jawa Timur yang berpenduduk 2.053.467 jiwa dan memiliki luas $714.243 \mathrm{~km}^{2}$ dengan kepadatan $3.218,6$ jiwa/ $\mathrm{km}^{2}$ yang terbagi dalam 18 kecamatan dan terdiri dari 353 kelurahan/desa. Kecamatan Krian di dominasi oleh permukiman pedesaan. Jenis permukiman ini banyak menghasilkan jenis sampah organik dari mayoritas kegiatan pertaniannya dan juga peternakannya [4].

Penerapan pengelolaan sampah dengan pola individual yang terjadi di kawasan pedesaan di Kabupaten Sidoarjo memiliki dampak negatif yakni, dapat menyebabkan polusi yang menjangkau daerah lain, kerusakan pada sumber air tanah dan tersumbatnya aliran air sungai di kawasan sekitarnya sehingga meningkatkan potensi bencana [5].

Dari uraian di atas maka perlu dilakukan studi mengenai potensi yang bisa dimanfaatkan, terutama untuk sampah organik yang dihasilkan oleh kegiatan industri tahu, peternakan, rumah pemotongan hewan (RPH), dan sampah organik dari kegiatan Pasar di Kecamatan Krian, Kabupaten Sidoarjo. 


\section{METODE PENELITIAN}

\section{A. Tahap Persiapan}

Pada tahap persiapan ini terdiri dari survey awal ke lokasi dan juga pendataan dan pembuatan alat - alat yang akan digunakan dalam penelitian. Alat - alat tersebut berupa alat alat bantu sampling dan lembar kuisoner yang akan disebar ke penduduk.

\section{B. Tahap Pengumpulan Data}

Jenis data yang dibutuhkan untuk menunjang studi potensi sampah organik ini adalah data primer yang didapatkan dari hasil pengambilan sampel dan analisa yang dilakukan di lapangan dan data sekunder yang dibutuhkan sebagai penunjang penelitian ini.

a) Pengumpulan Data Sekunder

Data sekunder merupakan informasi yang dikumpulkan bukan untuk kepentingan studi yang sedang dilakukan saat ini tetapi untuk beberapa tujuan lain. Data sekunder biasanya diperoleh dari dinas atau instansi pemerintah terkait atau instansi lainnya. Data-data sekunder yang digunakan dalam penelitian ini antara lain: Data dari Dinas Kebersihan dan Pertamanan Kabupaten Sidoarjo, Badan Pusat Statistik Kabupaten Sidoarjo, Dinas Pertanian, Perkebunan, dan Peternakan Kabupaten Sidoarjo, dan Dinas Pasar Kabupaten Sidoarjo.

Pengumpulan data ini bertujuan untuk mengetahui kondisi pengelolaan sampah dan kondisi eksisting di Kecamatan Krian, Kabupaten Sidoarjo.

b) Pengumpulan Data Primer

Data primer merupakan informasi yang dikumpulkan terutama untuk tujuan penelitian yang sedang dilakukan. Data primer diperoleh dari penelitian dan pengamatan langsung di lapangan. Data-data primer yang dibutuhkan dalam penelitian ini antara lain:

- Data timbulan dan komposisi sampah

Data timbulan sampah ini diperoleh melalui sampling di sumber sampah yang telah ditentukan (kawasan industri, fasilitas umum, dan kawasan pemukiman) di Kecamatan Krian, Kabupaten Sidoarjo. Pengukuran dan perhitungan sampel timbulan dan komposisi sampah mengacu pada di SNI 19-3964-1994 tentang metode pengambilan dan pengukuran sampel timbulan dan komposisi sampah. Satuan yang digunakan dalam pengukuran timbulan sampah adalah volume basah ( $\mathrm{m}^{3} /$ hari) dan berat basah $(\mathrm{kg} / \mathrm{hari})$.

- Data densitas sampah

Data densitas sampah ini diperoleh melalui perhitungan dengan rumus sebagai berikut:

$$
\begin{array}{ll}
\mathbf{p} & =\mathbf{m} / \mathbf{v} \\
\mathrm{p} & =\text { densitas sampah }\left(\mathrm{kg} / \mathrm{m}^{3}\right) \\
\mathrm{m} & =\text { berat sampah }(\mathrm{kg}) \\
\mathrm{v} & =\text { volume } \operatorname{sampah}\left(\mathrm{m}^{3}\right)
\end{array}
$$

\section{HASIL DAN PEMBAHASAN}

\section{A. Hasil Pengukuran Sentra Industri Tahu}

Data yang diperoleh dari pengukuran langsung di lapangan adalah berat ampas tahu sisa produksi dan berat abu sisa

pembakaran dari tungku pembakaran pabrik tahu.

Untuk unit yang diambil sebagai sumber sampling sebanyak 9 unit pabrik tahu dengan metode stratified random sampling. Sampling dilakukan di pabrik tahu yang sudah terklasifikasi sesuai besar kecilnya jumlah bahan baku produksi kedelai per harinya. Hal ini dikarenakan perbedaan jumlah bahan baku produksi yang dirasa terlalu besar, maka untuk rata-rata jumlah berat timbulan ampas tahu per harinya dibedakan menjadi 3 kelas/macam yaitu produksi tinggi, sedang, dan rendah. Hal ini juga bertujuan agar nilai yang diperoleh juga lebih akurat dan representatif.

$$
\begin{array}{ll}
\text { Kapasitas Produksi Tinggi } & \geq 2000 \mathrm{~kg} / \mathrm{hari} \\
\text { Kapasitas Produksi Sedang } & 1000-2000 \mathrm{~kg} / \mathrm{hari} \\
\text { Kapasitas Produksi Rendah } & <1000 \mathrm{~kg} / \mathrm{hari}
\end{array}
$$

Berikut daftar Industri Tahu yang di lakukan pengukuran timbulan sampah pada Tabel 1:

Tabel 1

Daftar Unit Industri Tahu

\begin{tabular}{|c|c|c|}
\hline No. & Industri & $\begin{array}{c}\text { Rata - Rata Jumlah Bahan } \\
\text { Baku Kedelai per Hari (kg) }\end{array}$ \\
\hline 1 & A & 2,700 \\
2 & B & 2,600 \\
3 & C & 2,000 \\
4 & D & 1,700 \\
5 & E & 1,500 \\
6 & F & 1,000 \\
7 & G & 1,000 \\
8 & H & 400 \\
9 & I & 150 \\
\hline
\end{tabular}

Setelah dilakukan pengukuran timbulan pada komposisi ampas tahu ini akan diketahui nilai rata - rata besaran timbulan masing - masing produksi. Berikut nilai besarannya:

Nilai berat ampas tahu untuk satu karung: $\mathbf{2 6 , 2 4} \mathbf{~ k g}$

Kapasitas Produksi

Tinggi:

Kapasitas Produksi

Sedang:

Kapasitas Produksi

Rendah:

Rata-rata (Kg):

Rata-rata (Kg):

Rata-rata (Kg):

Berikut data jumlah berat timbulan ampas tahu per hari pada Tabel 2:

Tabel 2

Jumlah Berat Timbulan Ampas Tahu per Hari

\begin{tabular}{|c|c|c|c|c|}
\hline No. & Industri & $\begin{array}{c}\text { Rata - Rata } \\
\text { Jumlah Ampas } \\
\text { Tahu per Hari } \\
\text { (Karung) }\end{array}$ & $\begin{array}{c}\text { Rata - Rata } \\
\text { Berat 1 } \\
\text { Karung } \\
\text { Ampas Tahu } \\
\text { (kg) }\end{array}$ & $\begin{array}{c}\text { Jumlah Berat } \\
\text { Ampas Tahu per } \\
\text { Hari (kg/hari) }\end{array}$ \\
\hline 1 & A & 215 & 27.00 & 5805.0 \\
2 & B & 200 & 26.40 & 5280.0 \\
3 & C & 150 & 26.47 & 3970.0 \\
\hline
\end{tabular}




\begin{tabular}{|c|c|c|c|c|}
\hline No. & Industri & $\begin{array}{c}\text { Rata - Rata } \\
\text { Jumlah Ampas } \\
\text { Tahu per Hari } \\
\text { (Karung) }\end{array}$ & $\begin{array}{c}\text { Rata - Rata } \\
\text { Berat 1 } \\
\text { Karung } \\
\text { Ampas Tahu } \\
\text { (kg) }\end{array}$ & $\begin{array}{c}\text { Jumlah Berat } \\
\text { Ampas Tahu per } \\
\text { Hari (kg/hari) }\end{array}$ \\
\hline 4 & D & 130 & 25.60 & 3328.0 \\
5 & E & 110 & 26.80 & 2948.0 \\
6 & F & 70 & 25.97 & 1817.7 \\
7 & G & 60 & 25.97 & 1558.0 \\
8 & H & 30 & 26.40 & 792.0 \\
9 & I & 10 & 25.60 & 256.0 \\
\hline \multicolumn{7}{r|}{ Rata - rata: } \\
\hline
\end{tabular}

Berikut ini merupakan hasil pengukuran timbulan abu pembakaran pada Tabel 3 dan grafik komposisi timbulan sentra industri tahu pada Gambar 1:

Tabel 3

Hasil Pengukuran Timbulan Abu Pembakaran

\begin{tabular}{|c|c|c|c|}
\hline No. & Industri & $\begin{array}{c}\text { Rata - Rata } \\
\text { Berat Abu per } \\
\text { Hari }(\mathbf{k g})\end{array}$ & $\begin{array}{c}\text { Rata - Rata } \\
\text { Volume Abu } \\
\text { per Hari }\left(\mathbf{m}^{3}\right)\end{array}$ \\
\hline 1 & A & 150 & 0.357 \\
2 & $\mathrm{~B}$ & 120 & 0.220 \\
3 & $\mathrm{C}$ & 90 & 0.149 \\
4 & $\mathrm{D}$ & 80 & 0.180 \\
5 & $\mathrm{E}$ & 80 & 0.147 \\
6 & $\mathrm{~F}$ & 60 & 0.098 \\
7 & $\mathrm{G}$ & 60 & 0.106 \\
8 & $\mathrm{H}$ & 20 & 0.043 \\
9 & $\mathrm{I}$ & 10 & 0.023 \\
\hline \multicolumn{4}{|c}{ Rata - rata: } \\
\hline
\end{tabular}
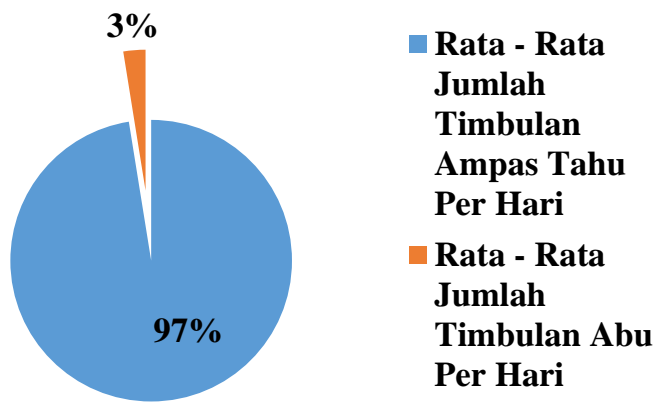

Gambar 1 Grafik Komposisi Timbulan Sentra Industri Tahu

\section{B. Hasil Pengukuran Peternakan Sapi Perah}

Terdapat total 464 ekor sapi perah yang terbagi menjadi 3 industri peternakan. Jenis komposisi sampah yang dihasilkan oleh peternakan sapi perah adalah kotoran sapi dan sisa pakan ternak. Setelah dilakukan pengukuran berat timbulan, rata rata berat kotoran per sapi per harinya sebesar 21,133 $\mathbf{K g} / \mathbf{h a r i}$. Sedangkan untuk sisa pakan ternak per sapi perharinya sebesar $\mathbf{2 , 0 0 8} \mathrm{Kg} / \mathrm{hari}$.
Berikut ini jumlah berat total timbulan kotoran sapi peternakan untuk tiap harinya pada Tabel 4 dan jumlah berat total timbulan sisa pakan ternak peternakan untuk tiap harinya pada Tabel 5:

Tabel 4

Jumlah Berat Total Timbulan Kotoran Sapi Peternakan

\begin{tabular}{|c|c|c|c|c|}
\hline $\begin{array}{l}\text { No } \\
\cdot\end{array}$ & Industri & $\begin{array}{c}\text { Jumlah } \\
\text { Ternak (Sapi } \\
\text { Perah) }\end{array}$ & $\begin{array}{c}\text { Jumlah } \\
\text { Kotoran per } \\
\text { Sapi per Hari } \\
\text { (kg) }\end{array}$ & $\begin{array}{c}\text { Jumlah Berat } \\
\text { Timbulan } \\
\text { Kotoran per } \\
\text { Hari (kg/hari) }\end{array}$ \\
\hline 1 & A & 400 & 21.100 & 8440.000 \\
2 & B & 48 & 21.933 & 1052.800 \\
3 & C & 16 & 20.367 & 325.867 \\
\hline \multicolumn{3}{|c|}{ Rata-rata: } \\
\hline
\end{tabular}

Tabel 5

Total Jumlah Berat Timbulan Sisa Pakan Ternak Peternakan

\begin{tabular}{|c|c|c|c|c|}
\hline No. & Industri & $\begin{array}{c}\text { Jumlah } \\
\text { Ternak } \\
\text { (Sapi } \\
\text { Perah) }\end{array}$ & $\begin{array}{c}\text { Jumlah Sisa } \\
\text { Pakan Ternak } \\
\text { per Sapi per } \\
\text { Hari (kg) }\end{array}$ & $\begin{array}{c}\text { Jumlah Berat } \\
\text { Timbulan Sisa } \\
\text { Pakan Ternak per } \\
\text { Hari (kg/hari) }\end{array}$ \\
\hline 1 & A & 400 & 1.6 & 640 \\
2 & B & 48 & 2.27 & 108.96 \\
3 & C & 16 & 2.1525 & 34.44 \\
\hline \multicolumn{4}{r}{ Rata-rata: } \\
\hline
\end{tabular}

Setelah diketahui jumlah total berat timbulan untuk kotoran dan sisa pakan ternak sapi perah untuk tiap harinya, maka bisa ditentukan persentase jumlah tiap komposisinya. Untuk komposisinya bisa dilihat pada grafik komposisi jumlah timbulan peternakan sapi perah per hari yang dijelaskan pada Gambar 2:

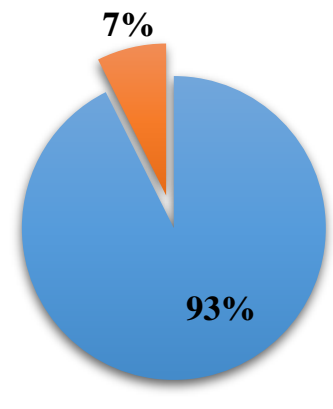

Gambar 2 Grafik Komposisi Jumlah Timbulan Peternakan Sapi Perah Per Hari.

\section{Hasil Pengukuran Rumah Pemotongan Hewan}

Pada Rumah Pemotongan Hewan yang berada di Kecamatan Krian ini tiap harinya menyembelih kurang lebih 100 ekor sapi [6]. Dalam pengukuran timbulan sampah di RPH ini terdapat 2 jenis komposisi sampah yang diukur, yaitu isi rumen sapi dan darah sapi.

Hasil pengukuran yang telah dilakukan menunjukkan bahwa rata - rata berat isi rumen sapi per ekornya sebesar 30,78 Kg. Sedangkan nilai rata - rata berat darah sapi per ekornya sebesar 6,533 Kg. Sebagai catatan, hasil sampling untuk jumlah darah per sapi di atas lebih sedikit jika 
dibandingkan dengan tinjauan pustaka maupun penelitian sebelumnya yang berkisar antara $15-20 \mathrm{~kg} / \mathrm{ekor}$ [7]. Hal ini dikarenakan banyaknya darah sapi yang tercecer di lantai pada waktu pengambilan sampel.

Berikut ini jumlah berat total timbulan isi rumen sapi per hari pada Tabel 6 dan jumlah berat total timbulan darah sapi per hari pada Tabel 7:

Tabel 6

Jumlah Berat Total Timbulan Isi Rumen Sapi per Hari

\begin{tabular}{|c|c|c|c|}
\hline No. & Hari Ke- & $\begin{array}{c}\text { Jumlah Sapi per } \\
\text { Hari (Sapi Potong) }\end{array}$ & $\begin{array}{c}\text { Jumlah Timbulan Isi Rumen } \\
\text { Sapi Per Hari (kg/hari) }\end{array}$ \\
\hline 1 & 1 & 112 & 3460.8 \\
2 & 2 & 118 & 3679.24 \\
3 & 3 & 115 & 3479.9 \\
\hline \multicolumn{2}{|c|}{ Rata - Rata: } & 115 & 3539.98 \\
\hline
\end{tabular}

Tabel 7

Jumlah Berat Total Timbulan Darah Sapi per Hari

\begin{tabular}{|c|c|c|c|}
\hline No. & Hari Ke- & $\begin{array}{c}\text { Jumlah Sapi per Hari } \\
\text { (Sapi Potong) }\end{array}$ & $\begin{array}{c}\text { Jumlah Timbulan Darah } \\
\text { Per Sapi Per Hari (kg/hari) }\end{array}$ \\
\hline 1 & 1 & 112 & 703.36 \\
2 & 2 & 118 & 861.4 \\
3 & 3 & 115 & 699.2 \\
\hline \multicolumn{2}{|c|}{ Rata - Rata: } \\
\hline
\end{tabular}

Dari rata - rata Tabel 6 dan Tabel 7 di atas dapat dibuat grafik komposisi timbulan limbah padat yang ada di RPH. Grafik komposisi timbulan limbah padat rumah pemotongan hewan yang terangkum pada gambar 3:

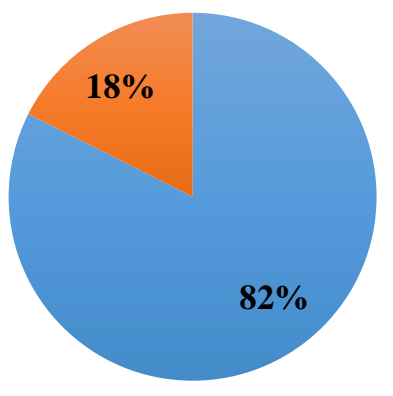

Jumlah
Timbulan Isi
Rumen Sapi Per
Hari (kg)
Jumlah
Timbulan Darah
Per Sapi Per
Hari (kg)

Gambar 3 Grafik Komposisi Timbulan Limbah Padat Rumah Pemotongan Hewan Krian

\section{Hasil Pengukuran Timbulan Pasar Krian}

Menurut Dinas Pasar Kabupaten Sidoarjo tahun 2013, pasar Krian memiliki luas $30.115 \mathrm{~m}^{2}$, dan terdapat total 2.196 pedagang. Dari 2.196 pedagang tadi 1.754 diantaranya merupakan pedagang buka dan 442 diantaranya merupakan pedagang tutup [8]. Di pasar Krian terdapat TPS yang dikelola langsung oleh Dinas Pasar. Terdapat 15 gerobak sampah dan 2 dump truck ukuran $8 \mathrm{~m}^{3}$ yang dioperasikan dan tiap harinya melakukan 2 kali ritasi.

Setelah dilakukan pengukuran berat timbulan per harinya nilai rata-rata total sampah pasar krian adalah $4947,89 \mathrm{~kg}$.

Berikut ini data hasil pengambilan contoh timbulan dan komposisi sampah di pasar krian pada Tabel 8:

Tabel 8

Data Hasil Pengambilan Contoh Timbulan dan Komposisi Sampah di Pasar Krian

$\begin{array}{clcc}\begin{array}{c}\text { Komponen } \\ \text { Sampah }\end{array} & \begin{array}{l}\text { Berat sampah } \\ \text { rata-rata }(\mathrm{kg})\end{array} & \begin{array}{c}\text { Persentase } \\ \text { rata-rata }(\%)\end{array} & \begin{array}{c}\text { Volume } \\ \text { sampah rata- } \\ \text { rata }\left(\mathrm{m}^{3}\right)\end{array}\end{array}$

\begin{tabular}{|c|c|c|c|}
\hline $\begin{array}{l}\text { Plastik } \\
\text { Dapat } \\
\text { dikomposkan }\end{array}$ & 5.183 & 5.061 & 0.092 \\
\hline Sisa sayuran & 77.399 & 75.573 & 0.305 \\
\hline Sisa makanan & 1.041 & 1.016 & 0.011 \\
\hline $\begin{array}{l}\text { Tongkol jagung } \\
\text { Sisa buah- } \\
\text { buahan }\end{array}$ & 0.858 & 0.838 & 0.016 \\
\hline $\begin{array}{l}\text { Sampah kebun } \\
\text { Sabut dan batok } \\
\text { kelapa }\end{array}$ & 0.402 & $\begin{array}{l}0.393 \\
4.684\end{array}$ & 0.014 \\
\hline Sisa daging & 1.618 & 1.580 & 0.014 \\
\hline \multicolumn{4}{|l|}{ Kertas } \\
\hline Kardus & 0.916 & 0.894 & 0.020 \\
\hline Non kardus & 1.203 & 1.174 & 0.020 \\
\hline $\begin{array}{l}\text { Kayu } \\
\text { Besek dan } \\
\text { bambu } \\
\text { non } \\
\text { besek/bambu }\end{array}$ & 1.657 & $\begin{array}{l}1.618 \\
0.421\end{array}$ & 0.060 \\
\hline \multicolumn{4}{|l|}{ Kaca } \\
\hline Kain & 0.160 & 0.156 & 0.004 \\
\hline $\begin{array}{l}\text { Karet dan kulit } \\
\text { Logam dan } \\
\text { elektronik }\end{array}$ & 0.165 & 0.161 & 0.006 \\
\hline Total & 101.843 & 100.00 & 0.677 \\
\hline
\end{tabular}

Untuk hasil pengukuran komposisi pasar krian, terdapat pada gambar 4:

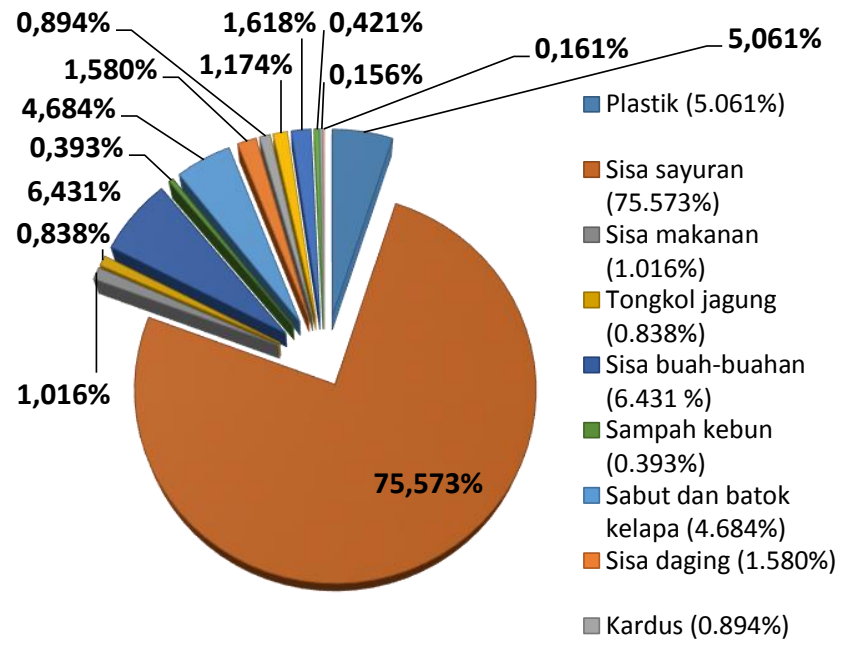

Gambar 4 Grafik Komposisi Sampah Pasar Krian 


\section{E. Rancangan Pengolahan Sampah}

Pada pembahasan ini akan direncanakan pengolahan sampah menjadi 3 produk, yaitu:

1. Kompos

2. RDF (Refuse Derived Fuel)

3. Biogas

Untuk pengolahan kompos dan RDF ini dikhususkan untuk sampah pasar dikarenakan komposisi sampah yang mendukung. Untuk pengolahan biogas dikhususkan untuk peternakan dan RPH..

Pengolahan kompos dan RDF direncanakan terletak di sekitar Pasar Krian dan dalam satu tempat terpadu/satu atap. Hal ini bertujuan untuk menghemat lahan yang ada dan memudahkan proses pengolahan. Sedangkan pengolahan biogas terdapat 2 tempat yang terpisah, yaitu di sekitar peternakan sapi perah dan di RPH.

Setelah dilakukan perhitungan, jumlah produksi jenis sampah yang dapat diolah menjadi kompos tiap harinya sebesar 4205,36 kg dan bervolume sebesar 17,39 $\mathrm{m}^{3}$,

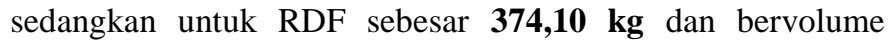
sebesar $\mathbf{1 , 5 5} \mathbf{~ m}^{\mathbf{3}}$ per harinya. Untuk biogas peternakan, sampah yang dapat diolah sebesar $10602,07 \mathrm{~kg}$ dan bervolume sebesar $\mathbf{8 , 8 4} \mathrm{m}^{3}$, untuk biogas RPH sebesar $3539,98 \mathrm{~kg}$ dan bervolume $\mathbf{3 , 7 4} \mathrm{m}^{3}$ per harinya.

Dari hasil timbulan sampah dan volume sampah tersebut dapat dianalisis luas lahan untuk masing masing lahan pengolahan yang ditabulasi pada Tabel 9 sampai Tabel 11:

Tabel 9

Total Kebutuhan Lahan Pengolahan Kompos dan RDF

\begin{tabular}{clr}
\hline No & \multicolumn{1}{c}{ Penggunaan Lahan } & Luas $\left.\mathbf{( m}^{\mathbf{2}}\right)$ \\
\hline 1 & Lahan pemilahan & 32 \\
2 & Lahan penampung sampah yang & 23 \\
3 & dikomposkan & 4,14 \\
4 & Lahan pencacahan & 178,608 \\
5 & Lahan pematangan penampung lindi & 0,31 \\
6 & Lahan pengayakan & 7,8 \\
7 & Lahan pengemasan & 9,47 \\
8 & Lahan RDF & 18 \\
9 & Lahan parker & 40 \\
10 & Gudang dan Kantor & 41 \\
\hline & Total
\end{tabular}

Tabel 10

Total Kebutuhan Lahan Pengolahan Biogas Peternakan

\begin{tabular}{clr}
\hline No & \multicolumn{1}{c}{ Penggunaan Lahan } & Luas $\left.\mathbf{( m}^{\mathbf{2}}\right)$ \\
\hline 1 & Lahan untuk Digester & 175,84 \\
2 & Lahan untuk penampung gas & 83,3 \\
\hline \multicolumn{2}{l}{ Total } & $\mathbf{2 5 9 , 1 4}$ \\
\hline
\end{tabular}

Tabel 11

Total Kebutuhan Lahan Pengolahan Biogas RPH

\begin{tabular}{clr}
\hline No & \multicolumn{1}{c}{ Penggunaan Lahan } & Luas $\left.\mathbf{( m}^{\mathbf{2}}\right)$ \\
\hline 1 & Lahan untuk Digester & 75,36 \\
2 & Lahan untuk penampung gas & 27,98 \\
\hline & Total & $\mathbf{1 0 3 , 3 4}$ \\
\hline
\end{tabular}

\section{F. Analisis Finansial}

Pada analisis finansial ini, meliputi biaya investasi, biaya operasional, hingga keuntungan yang diperoleh. Dalam perhitungan analisis finansial pengolahan kompos, RDF, dan biogas ini terdapat beberapa asumsi yang digunakan berdasarkan pada data yang reliable. Contohnya seperti harga sewa lahan, biaya air, biaya listrik, gaji pekerja dan sebagainya.

Dari hasil analisis perhitungan didapatkan rincian analisis finansial pengolahan kompos, RDF, dan biogas sebagai berikut:

- Biaya investasi yang diperlukan untuk desain teknologi pengolahan kompos dan RDF sebesar Rp 445.675.000.

- Biaya investasi yang diperlukan untuk desain teknologi pengolahan biogas untuk peternakan sapi perah sebesar Rp. 684.650.000 dan pengolahan biogas untuk rumah pemotongan hewan sebesar Rp. 293.150.000.

- Biaya operasional yang diperlukan untuk desain teknologi pengolahan kompos dan RDF sebesar Rp. 193.132.291.

- Biaya operasional yang diperlukan untuk desain teknologi pengolahan biogas peternakan dan RPH sebesar Rp. 241.787.933 dan Rp. 144.883.905.

- Jumlah keuntungan yang didapat pengolahan kompos dan RDF sebesar Rp. 253.938.445,00 per tahun.

- Jumlah keuntungan yang didapat pengolahan biogas di peternakan sapi Kelurahan Tropodo sebesar Rp. 131.613.525 per tahun.

- Jumlah keuntungan yang didapat pengolahan biogas di RPH sebesar Rp. 34.437.203 per tahun.

\section{KESIMPULAN}

Berdasarkan penelitian yang telah dilakukan, didapatkan beberapa kesimpulan yaitu:

1. Jumlah timbulan dan komposisi yang didapatkan sebagai berikut:

a. Jumlah timbulan limbah padat sentra industri tahu yang berupa ampas tahu adalah sebesar 5018,33 kg/hari untuk kapasitas produksi tinggi; 2412,92 kg/hari untuk kapasitas produksi sedang; dan $\mathbf{5 2 4}$ kg/hari untuk kapasitas produksi rendah.

b. Jumlah timbulan limbah padat sentra peternakan sapi perah yang berupa kotoran sapi adalah sebesar 3272,889 kg/hari; dan sisa pakan ternak adalah sebesar 261,133 kg/hari.

c. Jumlah timbulan limbah padat Rumah Pemotongan Hewan (RPH) yang berupa isi rumen adalah sebesar 3539,98 kg/hari; dan darah sapi sebesar 754,65 kg/hari. 
d. Jumlah timbulan limbah padat pasar krian adalah sebesar 4947,89 kg/hari dengan komposisi: sampah biodegradable $(92,554 \%)$; dan lainnya $(7,446)$ non-biodegradable.

2. Keuntungan yang didapat untuk pengolahan kompos dan RDF sebesar Rp. 253.938.445,00 per tahun. Untuk keuntungan biogas di peternakan sapi perah Kelurahan Tropodo dan RPH Krian sebesar Rp. 131.613.525,00 dan Rp. 34.437.203,00 per tahun.

\section{DAFTAR PUSTAKA}

[1] Hadiwiyoto, S. 1983. Penanganan dan Pemanfaatan Sampah. Yayasan Idayu. Jakarta.

[2] American Public Health Association (APHA), American Water Works Association (AWWA), and Water Environment Federation (WEF), 2005. Standard Methods For The Examination Of Water And Wastewater. 20th Ed., Washington, D.C.

[3] Tchobanoglous, G, Thiesen, H, dan Vigil S. 1993. Integrated Solid Waste Management. McGraw Hill, Singapore.

[4] BPS (Badan Pusat Statistik) Provinsi Jawa Timur, 2013, Sidoarjo Dalam Angka 2013, Badan Pusat Statistik Kabupaten Sidoarjo, Sidoarjo.

[5] Dinas Pertanian, Perkebunan, dan Peternakan Kabupaten Sidoarjo. 2013. Data Rumah Pemotongan Hewan Krian, Kabupaten Sidoarjo 2014. Dinas Pertanian, Perkebunan, dan Peternakan Kabupaten Sidoarjo. Sidoarjo.

[6] Anonim, 1994. Pelatihan PLP Kepala Seksi Bidang Persampahan. Departemen P.U. Direktorat Jenderal Cipta Karya Bagian Proyek Pembinaan Teknik, PLP Jakarta.

[7] Baller, G., Bethke, U. \& Wiemer, H.J. 1982. The Situation Regarding The Possibilities of Waste Utilization in The Food Industry "Gurke III". Research Report 10301309703 Part I, Schlachthoefe, on behalf of The Federal Environment Bureau.

[8] Dinas Pasar Kabupaten Sidoarjo. 2013. Data Pasar Kabupaten Sidoarjo 2013. Dinas Pasar Kabupaten Sidoarjo. Sidoarjo. 